
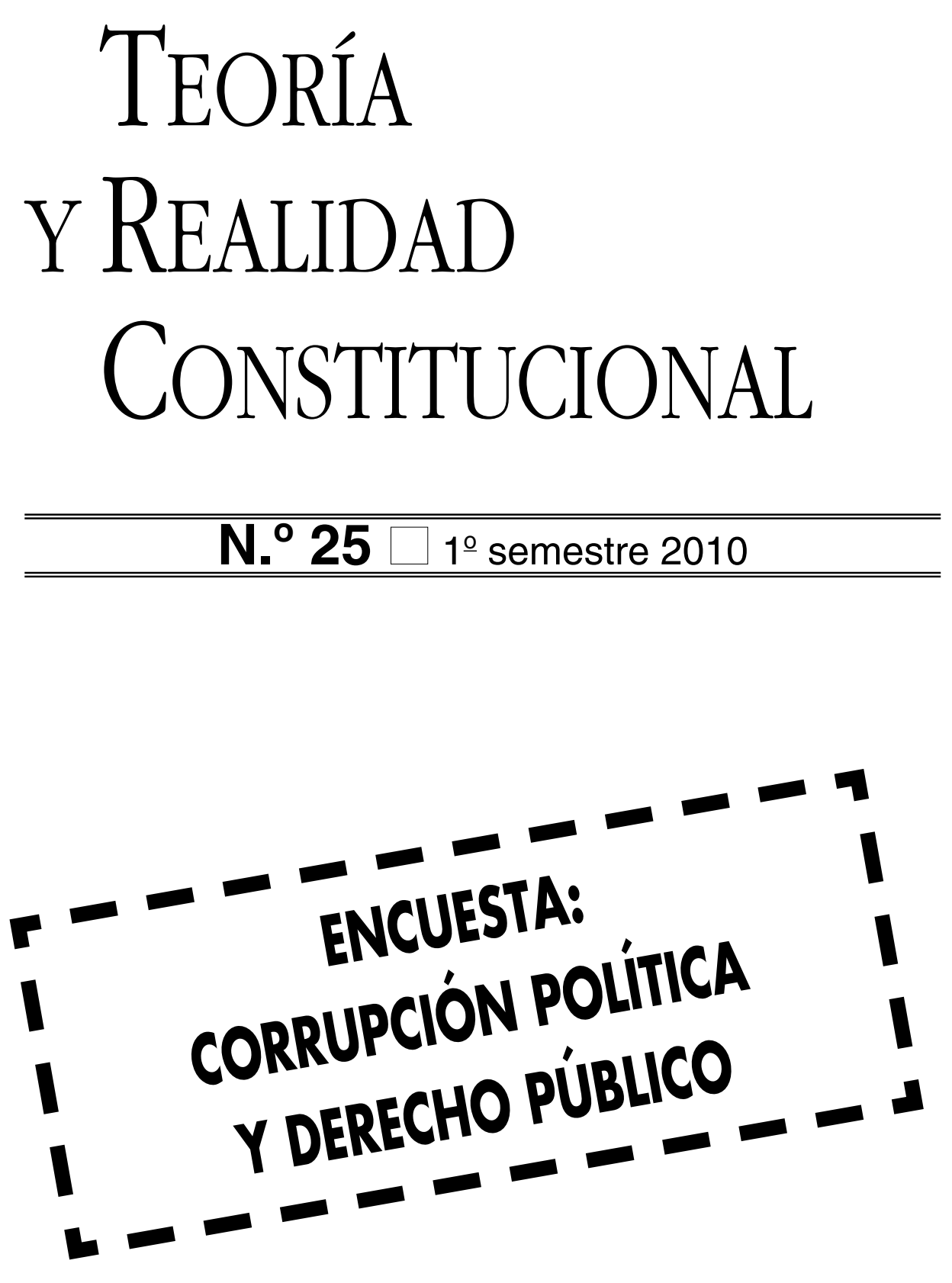


\title{
III PREMIO DE LA REVISTA TEORÍA Y REALIDAD CONSTITUCIONAL PARA ARTÍCULOS CIENTÍFICOS DE CONSTITUCIONALISTAS JOVENES
}

\author{
B A S E S
}

PRIMERA

Podrán concurrir juristas que no hayan cumplido los 35 años de edad, no pertenezcan a los cuerpos de Catedráticos y/o de Profesores Titulares de Universidad y no sean profesores o colaboradores de la Universidad Nacional de Educación a Distancia.

\section{SEGUNDA}

Se podrán presentar a este Premio artículos, inéditos, de extensión superior a veinte e inferior a treinta y cinco folios a dos espacios, incluidos sumario y notas a pié de página.

El tema es libre, aunque habrá de pertenecer al que tradicionalmente se considera el ámbito de nuestra disciplina. Se valorará naturalmente la calidad del trabajo y también el interés del tema sobre el que verse.

Junto al texto en soporte papel del artículo, firmado con pseudónimo, se acompañará soporte informático (CD o diskette) que contenga dicho texto y, en sobre cerrado aparte, los datos del autor, así como un breve currículum del mismo con especificación de su dirección, fotocopia de DNI y fecha de nacimiento.Nunca se hará constar el nombre ni los apellidos del autor del artículo, la infracción de este requisito será insubsanable y conllevará la exclusión del artículo.

\section{TERCERA}

Los premios serán tres. El Primero dotado con novecientos Euros. El Segundo dotado con seiscientos Euros. El Tercero dotado con cuatrocientos cincuenta Euros. 
Los artículos premiados serán publicados en la sección de estudios del primer número ordinario de la Revista convocante que se publique tras el fallo del tribunal del certamen. El Jurado podrá además otorgar los accésits honoríficos que estime pertinentes a la vista de otros artículos que juzgue merecedores de galardón proponiendo su publicación a los respectivos autores.

\section{CuARTA}

El Jurado tendrá la siguiente composición: Presidente, el Director de la Revista convocante. Vocales, seis catedráticos o profesores titulares de la asignatura, elegidos por el Consejo de Redacción de la Revista cuidando que queden representadas las distintas corrientes científicas que actualmente existen en nuestra disciplina. Secretario sin voto, uno de los Secretarios de la Revista, designado al efecto. Las decisiones se adoptarán por mayoría simple y se reflejarán en el correspondiente acta.

\section{QUINTA}

Los artículos referidos en la base segunda deberán llegar, en sobre cerrado y dirigido a "Sr. Director de la Revista Teoría y Realidad Constitucional, Departamento de Derecho Político. Facultad de Derecho de la UNED, c/ Obispo Trejo $\mathrm{n}^{\circ}$ 2, Ciudad Universitaria. Madrid", antes del 15 de noviembre de 2010. Se acusará recibo de los mismos a su autor.

\section{SEXTA}

El fallo del jurado será notificado mediante carta, por su Secretario a todos los autores que concurran a este premio.

\section{SÉPTIMA} bases.

La participación en este premio presupone la aceptación de todas sus 